\title{
Analysis of clinicopathological characteristics, $M Y B$ rearrangement and prognostic factors in salivary adenoid cystic carcinoma
}

\author{
JING HAN $^{1 *}$, CHUNYE ZHANG $^{2 *}$, TING GU $^{2}$, XI YANG ${ }^{1}$, LONGWEI HU $^{1}$, \\ ZHEN TIAN $^{2}$, JIANG LI $^{2}$ and CHENPING ZHANG ${ }^{1}$ \\ Departments of ${ }^{1}$ Oral and Maxillofacial-Head and Neck Oncology and ${ }^{2}$ Oral Pathology, \\ Ninth People's Hospital, Shanghai Jiao Tong University School of Medicine, Shanghai 200011, P.R. China
}

Received April 26, 2018; Accepted November 23, 2018

DOI: $10.3892 /$ ol.2019.9935

\begin{abstract}
Recent studies have indicated that a recurrent $\mathrm{t}(6 ; 9)(\mathrm{q} 22-23 ; \mathrm{p} 23-24)$ chromosomal translocation in salivary adenoid cystic carcinoma (ACC) results in a MYB proto-oncogene transcription factor-nuclear factor I/B (MYB-NFIB) gene fusion, which has not previously been detected in any non-ACC carcinomas of the head and neck. In the present study, data on clinical factors affecting the survival rate of patients with salivary ACC from a single institution was retrospectively analyzed, and the frequency of $M Y B$ gene rearrangement determined. A total of 97 patient cases were analyzed, and young adults presenting with ACC ( $<40$ years old) accounted for $19.6 \%$ of all patients $(n=19)$. A total of $70.1 \%$ $(n=68)$ displayed neurological symptoms, including pain, paraesthesia, tongue deviation, and facial paralysis. A marked majority of the analyzed tumors $(85.6 \%)$ displayed evidence of $M Y B$ rearrangement. $M Y B$ rearrangement was significantly higher in patients with late Tumor-Node-Metastasis (TNM) stage cancer compared with that in patients with early TNM stage $(\mathrm{P}=0.033)$, as detected by a dual color $M Y B$ break-apart fluorescence in situ hybridization probe. Kaplan-Meier analysis revealed significant differences in patient overall survival (OS) time with regard to age, gender, TNM stage,
\end{abstract}

Correspondence to: Professor Chenping Zhang, Department of Oral and Maxillofacial-Head and Neck Oncology, Ninth People's Hospital, Shanghai Jiao Tong University School of Medicine, 639 Zhi Zao Ju Road, Shanghai 200011, P.R. China

E-mail: zhang.chenping@hotmail.com

Dr Jiang Li, Department of Oral Pathology, Ninth People's Hospital, Shanghai Jiao Tong University School of Medicine, 639 Zhi Zao Ju Road, Shanghai 200011, P.R. China

E-mail: lijiang182000@126.com

*Contributed equally

Key words: salivary adenoid cystic carcinoma, young age, $M Y B$ rearrangement, prognosis neurological symptoms, margin status and $M Y B$ rearrangement. Specifically, young age was significantly associated with a shorter OS time. In summary, the present study suggested that young patients with salivary ACC presented with a worse prognosis, in contrast to the majority of patients with salivary ACC. Moreover, $M Y B$ alterations exhibited a high positive rate in salivary ACC, and therefore, the absence of $M Y B$ rearrangements may be associated with a better prognosis.

\section{Introduction}

Adenoid cystic carcinoma (ACC) is a rare malignancy that is able to exist at various sites within the body, although it is most commonly localized to the salivary gland (1). Salivary ACC displays characteristic features, including biological behavior diversity and histological heterogeneity (2). Patients diagnosed with salivary ACC usually present with a poor prognosis due to metastasis to distant organs, the high risk of relapse and the propensity of the tumor to invade the peripheral nerves. The majority of patients diagnosed with salivary ACC succumb between 5 and 20 years post-diagnosis (3-5).

To understand the course and behavior of the disease, a number of studies have focused on identifying specific prognostic factors for salivary ACC. However, few clinical parameters are associated with a poor prognosis, including advanced Tumor-Node-Metastasis (TNM) stage (6), perineural invasion and solid histological pattern (5,7-10). Moreover, assessment of the clinical parameters alone is not sufficient to accurately predict the clinical outcome of patients with salivary ACC. Therefore, molecular prognostic factors may be beneficial for a more accurate prediction of clinical outcome.

Previous studies have demonstrated that a recurrent $t(6 ; 9)$ (q22-23;p23-24) chromosomal translocation in salivary ACC results in the fusion of the MYB proto-oncogene transcription factor $(M Y B)$ gene with the nuclear factor I/B (NFIB) gene. Notably, the $M Y B-N F I B$ gene fusion has not been observed in any non-ACC carcinomas of the head and neck to date (11). The fusion gene fragment is predominantly $M Y B$, leading to the overexpression of $M Y B$ mRNA and a subsequent increase in protein expression level (12). Clinical and differential diagnoses of ACC have relied on the detection of molecular 
biomarkers, including $M Y B-N F I B$ gene fusion or $M Y B$ activation by fluorescence in situ hybridization (FISH) analysis, or immunohistochemical staining of MYB proteins (13-15). However, due to the small number of cases (and the potential possession of multiple primary cancer sites), the association between $M Y B$ rearrangement and clinical prognosis remains controversial $(2,16-21)$.

The purpose of the present study was to retrospectively analyze the clinical factors affecting the survival of patients with salivary ACC, and to identify the frequency of the rearrangement of $M Y B$ using FISH, in order to establish the association between $M Y B$ rearrangement and the survival rate or prognosis of patients with salivary ACC.

\section{Materials and methods}

Participants and recruitment. A total of 97 records of patients with ACC of the head and neck were analyzed. All patients were treated from January 2007 to December 2014 at the Shanghai Ninth People's Hospital, Shanghai Jiao Tong University. The inclusion criteria were as follows: i) Location of the tumor in major or minor salivary gland; ii) demographic and complete clinicopathological data; iii) radical surgery without preoperative therapy; and iv) availability of surgical specimens in formalin-fixed paraffin-embedded blocks. The study was approved by the Review Board of the Shanghai Ninth People's Hospital. Clinical, pathological, treatment and follow-up data were obtained from patient medical records. Young adult (YA) ACC patients were classed as $<40$ years old $(n=19)$, middle-aged (MA) patients were between 41 and 65 years old at disease onset $(n=60)$ and old-aged (OA) patients were $>65$ years of age at onset $(n=18)$. Two experienced pathologists reviewed the histological specimens. The histological grade was determined according to the following criteria: Grade 1, no solid component; grade 2, solid component $<30 \%$; and grade 3 , solid component $\geq 30 \%$. Margins were defined as positive if the tumor was detected at the resection margin. Patient information is displayed in Table I.

Information collection. The follow-up information for 94 cases was obtained by case record review and return visits. Follow-up time was defined as the time from initial presentation at the institution for the tumor of interest to the date of last contact or mortality for overall survival (OS) assessments. The endpoint investigated was OS, which was defined as the time in months from surgery to mortality from any cause.

FISH analysis. FISH was performed on formalin-fixed paraffin-embedded sections with a thickness of $5 \mu \mathrm{m}$ using a commercially available MYB Dual Color Break-Apart Probe (cat no. ZTV-Z-2143-200; ZytoVision GmbH, Bremerhaven, Germany). The probe is designed to detect translocations involving the chromosomal region 6q23.3 harboring the $M Y B$ gene, and has two probes labeled with green and orange fluorochromes that hybridize at the $5^{\prime}$ and 3 'ends of the $M Y B$ gene, respectively. Analysis was conducted as described previously (19). A cell number $>30$ among 100 isolated cells indicated $M Y B$ abnormalities (16). Cells with a normal pattern presented as two fusion signals. $M Y B$ abnormalities present either with typical rearrangement (one fusion and another with separate orange and green signals), deletion (one fusion and only one other orange or green signal) or amplification (more than two orange and/or green signals).

Statistical analysis. Statistical analyses were performed using the SPSS software package (version 13.0; SPSS, Chicago, IL, USA). The association of $M Y B$ with clinical parameters was determined using the $\chi^{2}$ test. Kaplan-Meier survival analysis and Cox multivariate analysis were used to evaluate the association between the clinical factors and OS of the patients with salivary ACC. The P-values in Table IV were obtained by log-rank (Mantel-Cox) test during Kaplan-Meier survival analysis. $\mathrm{P}<0.05$ was considered to indicate a statistically significant difference.

\section{Results}

Clinicopathological features and follow-up information. The clinical data and histological features of 97 patients with salivary ACC are presented in Table I. Notably, among the 97 patients, follow-up information could only be collected from 94 patients. The cohort included 45 females (46\%) and 52 males (54\%), resulting in a male-to-female $(\mathrm{M}: \mathrm{F})$ ratio of $1: 0.87$. The age of the patients at the time of diagnosis ranged from 20 to 83 years, with a mean age of 53.9 years. YA patients with salivary ACC $(n=19 ; 19.6 \%)$ were defined as those $<40$ years of age, MA patients $(n=60 ; 61.9 \%)$ as between 41 and 65 years of age at onset and OA patients $(n=18 ; 18.6 \%)$ as $>65$ years of age at onset. The incidence of ACC in the minor salivary glands $(n=63 ; 64.9 \%)$ was higher compared with that in the major salivary glands $(n=34 ; 35.1 \%)$. The palate was the most frequent location for salivary ACC $(n=28 ; 28.9 \%)$. Overall, the tumor evaluation according to the TNM staging system identified 12 cases $(12.4 \%)$ of $\mathrm{T} 1,27$ cases $(27.8 \%)$ of T2, 26 cases $(26.8 \%)$ of $\mathrm{T} 3$ and 32 cases $(33.0 \%)$ of $\mathrm{T} 4$ cancer at diagnosis.

The median time to presentation for treatment was 6 months (range, 0.5-125 months). There were 7 cases in which the presentation was delayed for over 60 months, including certain patients presenting with slow-growing tumors, 1 patient initially diagnosed with trigeminal neuralgia and another patient treated for glossopharyngeal neuralgia.

The majority of patients $(n=68 ; 70.1 \%)$ presented with neurological symptoms, including pain, paresthesia, tongue deviation and facial paralysis, while the remainder $(n=29$; $29.9 \%$ ) had no apparent symptoms or presented with other symptoms, including rapid growth of a mass, nasal obstruction or bleeding, and ulceration. The lesions of the palate frequently manifested as ulcers with numbness or pain. Parotid lesions frequently appeared as facial skin needle- or electric shock-like pain, in addition to facial paralysis. The floor of the mouth, tongue and sublingual gland lesions displayed different symptoms, including tongue numbness, pain and tongue deviation. The lesions of the maxillary sinus were frequently accompanied by epistaxis and diplopia. Histopathological evaluation of the tumor specimens identified 66 cases at grade 1, 14 cases at grade 2 and 17 cases at grade 3 . A total of 63 cases (64.9\%) displayed evidence of perineural invasion, while vascular infiltration was observed in 16 cases (16.5\%). Moreover, 42 cases $(43.3 \%)$ presented with positive surgical margins. Metastases to the regional lymph nodes were noted in 5 cases (5.2\%). All the cervical lymph node metastases occurred in T3 and T4 
Table I. Clinical and histological characteristics $(n=97)$, and follow-up information ( $n=94)$ of patients with salivary adenoid cystic carcinoma.

\begin{tabular}{lc}
\hline Characteristic & Cases, $\mathrm{n}$ \\
\hline Age, years & \\
$\leq 40$ & 19 \\
$41-65$ & 60 \\
$>65$ & 18 \\
Sex & \\
Male & 52 \\
Female & 45 \\
Site & \\
Major & 34 \\
Minor & 63 \\
TNM stage & \\
I & 12 \\
II & 27 \\
III & 26 \\
IV & 32
\end{tabular}

Neurological symptoms

Yes

No

Histopathological grade

1

2

3

Perineural invasion

Yes

No

Vascular invasion

Yes

No

Margin status

Positive

Negative

Lymph node metastasis

Positive

Negative

Treatment

Surgery

Surgery and radiation

Surgery and chemoradiation

New recurrence

Yes

No

Distant metastasis

Prior to treatment

Following initial treatment

No

Table I. Continued.

Characteristic

Cases, $\mathrm{n}$

Last known vital status

Alive free of tumor $\quad 32$

Alive with tumor $\quad 38$

$\begin{array}{ll}\text { Succumbed } & 24\end{array}$

TNM, Tumor-Node-Metastasis.

Table II. Rearrangements of $M Y B$ detected by fluorescence in situ hybridization.

\begin{tabular}{lc}
\hline MYB rearrangements & Number \\
\hline Split signal & 71 \\
Split and 5'-part amplification & 5 \\
Loss of 3'-part & 4 \\
Loss of 5'-part & 2 \\
Copy number amplification & 1 \\
Normal & 14
\end{tabular}

$M Y B$, MYB proto-oncogene transcription factor.

(1)

5

2

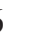

MYB rearrangement. Using a dual color MYB break-apart 97 cases. The typical patterns of $M Y B$ rearrangements with an intact signal (fused orange/green signals) (Fig. 1A) and a split signal (separated orange and green signals), indicating a breakpoint within the $M Y B$ gene (Fig. 1B), compared with the intact signal, were observed in 71 tumors. Gain of one or more green signals was apparent in 5 cases, indicating selective amplification of the 5 'end of $M Y B$ (Fig. 1C), and multiple pairs of fusion signals were observed in one case, indicating gain of 41 MYB copies (Fig. 1D) (Table II). A typical pattern with one 
Table III. Associations between clinicopathological parameters and MYB rearrangement.

\begin{tabular}{|c|c|c|c|}
\hline \multirow[b]{2}{*}{ Parameter } & \multicolumn{2}{|c|}{$M Y B$ rearrangement, $\mathrm{n}(\%)$} & \multirow[b]{2}{*}{ P-value } \\
\hline & With $(\mathrm{n}=81)$ & Without $(n=13)$ & \\
\hline Age, years & & & 0.157 \\
\hline$\leq 40$ & $18(100.0)$ & $0(0.0)$ & \\
\hline $41-65$ & $48(82.8)$ & $10(17.2)$ & \\
\hline$>65$ & $15(83.3)$ & $3(16.7)$ & \\
\hline Sex & & & 0.372 \\
\hline Male & $38(90.5)$ & $4(9.5)$ & \\
\hline Female & $43(82.7)$ & $9(17.3)$ & \\
\hline Site & & & 0.788 \\
\hline Major & $28(87.5)$ & $4(12.5)$ & \\
\hline Minor & $53(85.5)$ & $9(14.5)$ & \\
\hline TNM stage & & & 0.033 \\
\hline $\mathrm{I} / \mathrm{II}$ & $29(76.3)$ & $9(23.7)$ & \\
\hline III/IV & $52(92.9)$ & $4(7.1)$ & \\
\hline Neurological symptoms & & & 0.995 \\
\hline Yes & $56(86.2)$ & $9(13.8)$ & \\
\hline No & $25(86.2)$ & $4(13.8)$ & \\
\hline Histopathological grade & & & 0.332 \\
\hline 1 & $54(83.1)$ & $111(16.9)$ & \\
\hline $2 / 3$ & $27(93.1)$ & $2(6.9)$ & \\
\hline Perineural invasion & & & 0.764 \\
\hline Yes & $53(86.9)$ & $8(13.1)$ & \\
\hline No & $28(84.8)$ & $5(15.2)$ & \\
\hline Vascular invasion & & & 0.119 \\
\hline Yes & $15(100.0)$ & $0(0.0)$ & \\
\hline No & $66(86.2)$ & $13(13.8)$ & \\
\hline
\end{tabular}

TNM, Tumor-Node-Metastasis; $M Y B$, MYB proto-oncogene transcription factor.

fusion signal and one green/ orange signal, indicating the loss of the $3^{\prime}$ end, was observed in 4 cases (Fig. 1E) and the loss of the 5 'end was observed in 2 cases (Fig. 1F).

The statistical significance between clinicopathological characteristics and $M Y B$ rearrangement in patients with salivary ACC patients was subsequently assessed (summarized in Table III). Only TNM stage was significantly associated with $M Y B$ rearrangement, wherein the late TNM stage was associated with higher $M Y B$ rearrangement $(\mathrm{P}=0.033)$. These results suggest that $M Y B$ rearrangement is associated with the progression of salivary ACC, which may be interpreted as an indicator of poor prognosis. Notably, $M Y B$ gene rearrangement was not statistically associated with any other clinicopathological variable.

Survival analyses. Kaplan-Meier analysis revealed significant differences in OS, dependent on age, sex, TNM stage, neurological symptoms, margin status and $M Y B$ rearrangement (Fig. 2; Table IV). For specific groups, the median survival times were absent, as until the end of the follow-up period, the overall survival rate in these groups remained at $>50 \%$.
Therefore, the method used to determine survival analysis could not provide the hazard ratio in the case of $>2$ groups. In multivariate analysis, YA was indicated to be significantly associated with a shorter OS time (Table V).

\section{Discussion}

Salivary ACC is one of the most common malignant tumors of the oral and maxillofacial region. In agreement with previous studies $(5,22,23)$, the present study indicated that salivary ACC originates more frequently from minor rather than major glands, and predominantly affects the palate.

Although previous studies have suggested that salivary ACC affects a wide age distribution and has no sex predilection $(5,24)$, the present results indicate that salivary ACC has a minor male predominance. Consistently, analysis using Kaplan-Meier survival curves revealed significant differences between men and women, with women having improved survival outcomes. Moreover, salivary ACC typically occurs in the fifth or sixth decade of life, although it may also present in YA patients $(25,26)$. Certain reports suggest that older age 
Table IV. Kaplan-Meier survival analysis for OS time in patients with salivary adenoid cystic carcinoma.

\begin{tabular}{|c|c|c|}
\hline Variable & OS time, months & P-value \\
\hline Age, years & & 0.001 \\
\hline$\leq 40$ & $47.518 \pm 6.708$ & \\
\hline $41-65$ & $91.381 \pm 4.246$ & \\
\hline$>65$ & $75.231 \pm 8.733$ & \\
\hline Sex & & 0.035 \\
\hline Male & $59.205 \pm 4.495$ & \\
\hline Female & $87.080 \pm 4.834$ & \\
\hline Site & & 0.109 \\
\hline Major & $61.076 \pm 4.629$ & \\
\hline Minor & $83.940 \pm 4.931$ & \\
\hline TNM stage & & 0.001 \\
\hline $\mathrm{I} / \mathrm{II}$ & $99.599 \pm 3.026$ & \\
\hline III/IV & $67.537 \pm 5.183$ & \\
\hline Neurological symptoms & & 0.014 \\
\hline Yes & $71.842 \pm 4.594$ & \\
\hline No & $98.241 \pm 3.929$ & \\
\hline Histopathological grade & & 0.082 \\
\hline 1 & $83.764 \pm 4.783$ & \\
\hline $2 / 3$ & $60.023 \pm 5.698$ & \\
\hline Perineural invasion & & 0.880 \\
\hline Yes & $59.356 \pm 3.719$ & \\
\hline No & $79.464 \pm 5.011$ & \\
\hline Vascular invasion & & 0.207 \\
\hline Yes & $56.333 \pm 7.342$ & \\
\hline No & $81.684 \pm 4.446$ & \\
\hline Margin status & & 0.011 \\
\hline Positive & $61.210 \pm 4.887$ & \\
\hline Negative & $88.098 \pm 4.828$ & \\
\hline Treatment & & 0.143 \\
\hline Surgery & $67.059 \pm 10.782$ & \\
\hline Surgery and radiation & $73.169 \pm 3,222$ & \\
\hline Surgery and chemoradiation & $72.810 \pm 11.052$ & \\
\hline$M Y B$ rearrangement & & 0.029 \\
\hline Yes & $55.582 \pm 3.842$ & \\
\hline No & $96.615 \pm 7.095$ & \\
\hline
\end{tabular}

TNM, Tumor-Node-Metastasis; OS, overall survival; MYB, MYB proto-oncogene transcription factor.

is a risk factor for lower survival rates in patients with salivary $\operatorname{ACC}(5,10,27,28)$. Accordingly, the present study revealed that the peak incidence of salivary ACC was amongst MA patients. The incidence of salivary ACC in YA patients was relatively low and represented a minority of cases. The association between YA and prognosis is a well-described phenomenon reported across multiple cancer types $(29,30)$. For example, in head and neck squamous cell carcinoma, young cancer patients presented with a worse prognosis (31). However, the prognosis of the YA patients in the context of salivary ACC has yet to be evaluated. The present results indicated that YA patients presented with a worse prognosis compared with MA and OA patients.

Patients with ACC frequently develop neurological symptoms in the early stages of the disease $(32,33)$. Neural spread away from a tumor frequently results in specific symptoms, including pain, muscle weakness and atrophy, depending on the nerves involved. Occasionally, pain may occur in the early stage of the disease until there is a noticeable swelling. In certain cases, the treatment of patients is delayed due to the initial diagnosis of trigeminal or glossopharyngeal neuralgia (22). Although the most common initial presentation is unclear, almost one-third of patients present with dysaesthesia. This symptom is important in the absence of clinically visible symptoms, as it may indicate an underlying neoplastic variation and warrant further investigation. Despite these observations, the association between histopathological perineural invasion and disease prognosis remains controversial $(28,34,35)$. Moreover, the connection between neurological symptoms and prognosis in patients with cancer is yet to be addressed. By contrast, the present results indicate that patients with neurological symptoms had a comparatively poor prognosis, but did not exhibit histopathological perineural invasion. These results suggested that patients with salivary ACC, but without neurological symptoms, had a relatively good prognosis, and were more likely to be misdiagnosed with other salivary gland tumors.

The present study confirmed previous studies indicating that TNM stage at diagnosis is the primary factor for survival prediction in patients with cancer $(5,7,8,36)$. Owing to the slow-growing nature and protracted clinical presentation of salivary ACC, patients are not always aware of the cancer until the rapid growth or metastasis stage. In the present study, there were 8 patients who presented with pulmonary metastasis during the time of diagnosis of the primary lesion. Moreover, lymph node involvement in the salivary ACC is uncommon. In the study by Min et al (24), 62 out of 616 (10.1\%) cases of lymph node metastasis were identified, with the most common primary site originating from the base of the tongue, mobile tongue and floor of the mouth. In the present study, metastases to the regional lymph nodes were determined in only 5 cases, which all occurred in T3 and T4 tumors, with 4 cases originating from the floor of the mouth and 1 case from the buccal mucosa.

Salivary ACC has notable heterogeneous morphology and contains tubular, cribriform, solid or mixed patterns. However, these histopathological features are not specific to salivary ACC and may also be present in other salivary gland tumors, including pleomorphic adenoma, basal cell adenoma, basal cell adenocarcinoma and polymorphous low-grade adenocarcinoma. Therefore, novel molecular biomarkers may encourage more accurate prediction of clinical outcome in patients with salivary ACC. Genetic alterations detected in tumors may be associated with the oncogenic process and potentially serve as diagnostic biomarkers. $M Y B-N F I B$ gene fusion and $M Y B$ activation have frequently been utilized as molecular biomarkers in clinical and differential diagnoses (13-15). However, studies investigating the expression of $M Y B$ in pleomorphic adenoma suggest that alterations in the $M Y B$ gene are not a definitive diagnostic biomarker (37). Moreover, as a potential diagnostic biomarker for ACC, the 
Table V. Univariate and Multivariate Cox analysis of variables considered for overall survival of salivary adenoid cystic carcinoma patients.

\begin{tabular}{|c|c|c|c|c|c|c|}
\hline \multirow[b]{2}{*}{ Variables } & \multicolumn{3}{|c|}{ Univariate } & \multicolumn{3}{|c|}{ Multivariate } \\
\hline & HR & $95 \%$ CI & $\mathrm{P}$-value & HR & $95 \%$ CI & P-value \\
\hline Age $(\leq 40$ vs. $>40)$ & 3.884 & $1.676-9.003$ & $0.002^{\mathrm{a}}$ & 2.921 & $1.191-7.142$ & $0.019^{\mathrm{a}}$ \\
\hline Margin status (positive vs. negative) & 3.014 & $1.228-7.396$ & $0.016^{\mathrm{a}}$ & 2.677 & $1.049-6.830$ & $0.039^{\mathrm{a}}$ \\
\hline Neurological symptoms (yes vs. no) & 5.137 & $1.202-21.966$ & $0.027^{\mathrm{a}}$ & 3.357 & $0.757-14.895$ & 0.111 \\
\hline TNM stage (III/IV vs. I/II) & 8.904 & 2.087-37.994 & $0.003^{\mathrm{a}}$ & 3.947 & $0.854-18.248$ & 0.079 \\
\hline Histopathology grade (2/3 vs. 1 ) & 2.585 & $1.053-6.347$ & $0.038^{\mathrm{a}}$ & 2.483 & $0.925-6.661$ & 0.071 \\
\hline Sex (male vs. female) & 0.676 & $0.274-1.688$ & 0.395 & & & \\
\hline Site (major vs. minor) & 0.968 & $0.545-1.720$ & 0.912 & & & \\
\hline Perineural invasion (yes vs. no) & 1.056 & $0.429-2.956$ & 0.906 & & & \\
\hline Vascular invasion (yes vs. no) & 1.880 & $0.692-5.180$ & 0.215 & & & \\
\hline MYB rearrangement (yes vs. no) & 0.035 & $0.000-4.223$ & 0.170 & & & \\
\hline
\end{tabular}

${ }^{\mathrm{a}} \mathrm{P}<0.05$. HR, hazard ratio; CI, confidence interval; TNM, Tumor-Node-Metastasis; $M Y B$, MYB proto-oncogene transcription factor.
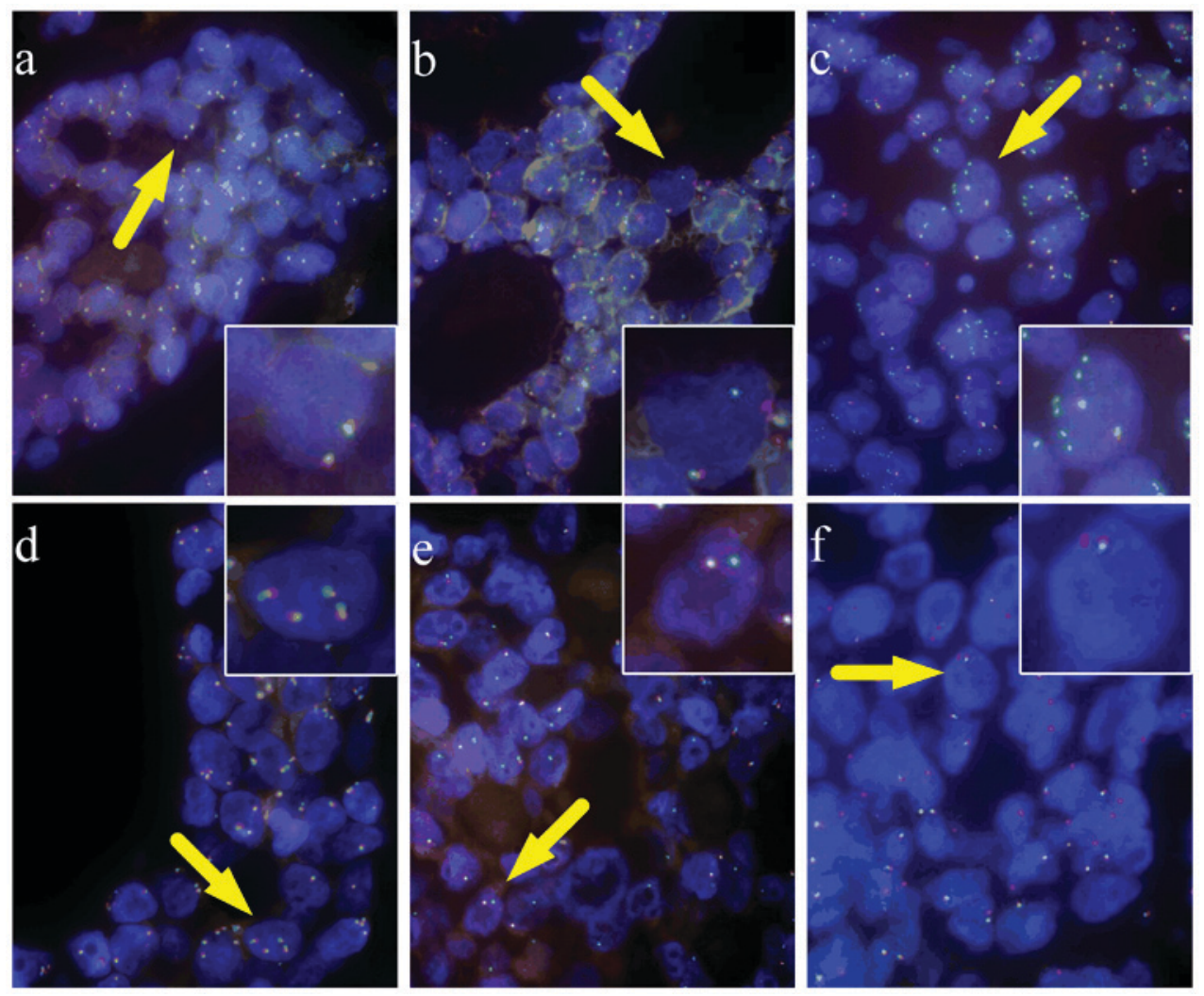

Figure 1. Rearrangements of MYB detected by fluorescence in situ hybridization. (A) Normal (x1,000, oil mirror), (B) split (x1,000, oil mirror), (C) 5'-part amplification (x1,000, oil mirror), (D) copy number amplification (x1,000, oil mirror), (E) loss of 3'-part and (F) loss of 5'-part (x1,000, oil mirror). Cells with a normal pattern present as two fusion signals. MYB abnormalities present either with typical rearrangement (one fusion and another separate orange and green signal), deletion (one fusion and only one other orange or green signal) or amplification (more than two orange and/or green signals). MYB, MYB proto-oncogene transcription factor.

specific association of $M Y B$ rearrangement with clinical features and the prognosis of salivary ACC have not been completely elucidated $(11,21)$.

FISH studies by Perron et al (38) indicated that MYB-NFIB gene fusion occurred in $86 \%$ of tumors, and that gene rearrangement due to chromatin instability frequently led to a loss of 6q24.1-6q27, more commonly in high histological grade cancer. Roden et al (20) detected 35 cases of lung ACC with the MYB break-apart probe, showing $100 \%$ specificity of $M Y B$ rearrangement in $41 \%$ of cases; however, there was no correlation between $M Y B$ rearrangement and clinical features or prognosis. Broz et al (2) detected 23 cases of salivary ACC, 

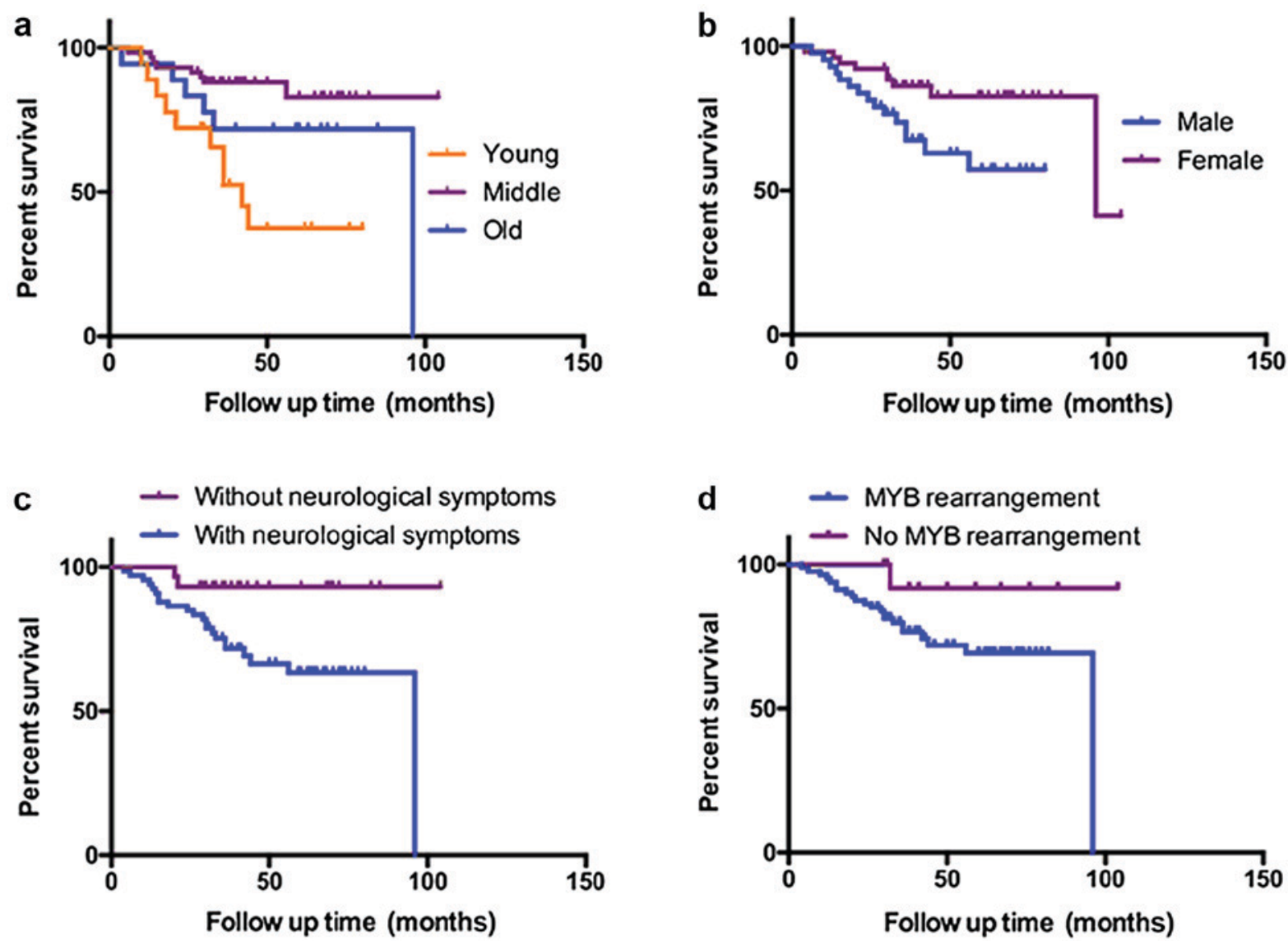

Figure 2. (A-D) Kaplan-Meier survival curves for salivary adenoid cystic carcinoma patients with different clinical characteristics and $M Y B$ rearrangement. $M Y B$, MYB proto-oncogene transcription factor.

with 15 cases positive for rearrangement and 8 cases with no rearrangement (2). There were no significant differences in age, sex, perineural invasion, the presence of hematogenic and nodal metastases, or degree of histopathological grading between patients with and without $M Y B$ rearrangement. Survival analysis revealed no statistically significant differences in survival between patients with and without $M Y B$ rearrangement; however, a lack of $M Y B$ alteration was associated with a better prognosis (2). In the present study, the vast majority of cases exhibited $M Y B$ isolation, and few cases displayed deletion or amplification of $M Y B$; there was no significant association between the different gene alterations and the histological phenotype of ACC. Survival analysis indicated significantly improved OS times in patients with no alterations in $M Y B$ compared with those in patients with $M Y B$ rearrangements, which is in agreement with the conclusions of Broz et al (2), despite their findings not being statistically significant.

Moreover, the present results suggested that YA patients with salivary ACC have a worse prognosis, which is significantly different from the majority of patients presenting with salivary ACC. Detection of $M Y B$ alterations by FISH could achieve a high positive detection rate in salivary ACC, which would facilitate clinical diagnosis, and the lack of $M Y B$ rearrangement may be associated with a better prognosis. Therefore, establishing the association between $M Y B$ rearrangement and prognosis may be beneficial for a greater understanding and the improved treatment of salivary ACC.

\section{Acknowledgements}

Not applicable.

Funding

The present study was supported by the Natural Science Fund of China (grant nos. 81372910 and 81302360).

\section{Availability of data and material}

The datasets used and/or analyzed during the present study are available from the corresponding author on reasonable request.

\section{Authors' contributions}

$\mathrm{JH}$ and $\mathrm{CYZ}$ were responsible for the study conception and design. TG and XY conducted experimental testing and follow-up. LWH and ZT collected the data and revised the manuscript. Data analysis and interpretation was conducted by JL and CPZ. All authors contributed to writing the manuscript and provided final approval.

\section{Ethics approval and consent to participate}

The present study was approved by the Review Board of the Ninth People's Hospital and informed consent was obtained from all participants. 


\section{Patient consent for publication}

Not applicable.

\section{Competing interests}

The authors declare that they have no competing interests.

\section{References}

1. Coca-Pelaz A, Rodrigo JP, Bradley PJ, Vander Poorten V, Triantafyllou A, Hunt JL, Strojan P, Rinaldo A, Haigentz M $\mathrm{Jr}$, Takes RP, et al: Adenoid cystic carcinoma of the head and neck--An update. Oral Oncol 51: 652-661, 2015

2. Broz M, Steiner P, Salzman R, Hauer L and Starek I: The incidence of MYB gene breaks in adenoid cystic carcinoma of the salivary glands and its prognostic significance. Biomed Pap Med Fac Univ Palacky Olomouc Czech Repub 160: 417-22, 2016.

3. Fordice J, Kershaw C, El-Naggar A and Goepfert H: Adenoid cystic carcinoma of the head and neck: Predictors of morbidity and mortality. Arch Otolaryngol Head Neck Surg 125: 149-52, 1999.

4. Spiro RH: Distant metastasis in adenoid cystic carcinoma of salivary origin. Am J Surg 174: 495-498, 1997.

5. Zhang CY, Xia RH, Han J, Wang BS, Tian WD, Zhong LP, Tian Z, Wang LZ, Hu YH and Li J: Adenoid cystic carcinoma of the head and neck: Clinicopathologic analysis of 218 cases in a Chinese population. Oral Surg Oral Med Oral Pathol Oral Radiol 115: 368-375, 2013.

6. Brierley JD, Gospodarowicz MK and Wittekind C (eds): TNM classification of malignant tumours (8th edition). Chichester, West Sussex, UK: Wiley-Blackwell. ISBN 978-1-4443-3241-4, 2017

7. Khafif A, Anavi Y, Haviv J, Fienmesser R, Calderon S and Marshak G: Adenoid cystic carcinoma of the salivary glands: A 20 -year review with long-term follow-up. Ear Nose Throat J 84 662, 664-667, 2005

8. Dodd RL and Slevin NJ: Salivary gland adenoid cystic carcinoma: A review of chemotherapy and molecular therapies. Oral Oncol 42: 759-769, 2006

9. Ciccolallo L, Licitra L, Cantú G and Gatta G; EUROCARE Working Group: Survival from salivary glands adenoid cystic carcinoma in European populations. Oral Oncol 45: 669-674, 2009.

10. Bhayani MK, Yener M, El-Naggar A, Garden A, Hanna EY, Weber RS and Kupferman ME: Prognosis and risk factors for early-stage adenoid cystic carcinoma of the major salivary glands. Cancer 118: 2872-2878, 2012.

11. Stenman G: Fusion oncogenes in salivary gland tumors: Molecular and clinical consequences. Head Neck Pathol 7 (Suppl 1): S12-S19, 2013.

12. Persson M, Andrén Y, Mark J, Horlings HM, Persson F and Stenman G: Recurrent fusion of MYB and NFIB transcription factor genes in carcinomas of the breast and head and neck. Proc Natl Acad Sci USA 106: 18740-18744, 2009.

13. Pusztaszeri MP, Sadow PM, Ushiku A, Bordignon P, McKee TA and Faquin WC: MYB immunostaining is a useful ancillary test for distinguishing adenoid cystic carcinoma from pleomorphic adenoma in fine-needle aspiration biopsy specimens. Cancer Cytopathol 122: 257-265, 2014.

14. Tian Z, Li L, Zhang CY, Gu T and Li J: Differences in MYB expression and gene abnormalities further confirm that salivary cribriform basal cell tumors and adenoid cystic carcinoma are two distinct tumor entities. J Oral Pathol Med 45: 698-703, 2016

15. Hudson JB and Collins BT: MYB gene abnormalities $t(6 ; 9)$ in adenoid cystic carcinoma fine-needle aspiration biopsy using fluorescence in situ hybridization. Arch Pathol Lab Med 138: 403-409, 2014.

16. West RB, Kong C, Clarke N, Gilks T, Lipsick JS, Cao H, Kwok S, Montgomery KD, Varma S and Le QT: MYB expression and translocation in adenoid cystic carcinomas and other salivary gland tumors with clinicopathologic correlation. Am J Surg Pathol 35: 92-99, 2011.

17. von Holstein SL, Fehr A, Persson M, Therkildsen MH, Prause JU, Heegaard S and Stenman G: Adenoid cystic carcinoma of the lacrimal gland: MYB gene activation, genomic imbalances, and clinical characteristics. Ophthalmology 120: 2130-2138, 2013.

18. D'Alfonso TM, Mosquera JM, MacDonald TY, Padilla J, Liu YF, Rubin MA and Shin SJ: MYB-NFIB gene fusion in adenoid cystic carcinoma of the breast with special focus paid to the solid variant with basaloid features. Hum Pathol 45: 2270-2280, 2014.
19. Rettig EM, Tan M, Ling S, Yonescu R, Bishop JA, Fakhry C and Ha PK: MYB rearrangement and clinicopathologic characteristics in head and neck adenoid cystic carcinoma. Laryngoscope 125: E292-E299, 2015.

20. Roden AC, Greipp PT, Knutson DL, Kloft-Nelson SM, Jenkins SM, Marks RS, Aubry MC and García JJ: Histopathologic and cytogenetic features of pulmonary adenoid cystic carcinoma. J Thorac Oncol 10: 1570-1575, 2015

21. Chen TY, Keeney MG, Chintakuntlawar AV, Knutson DL, Kloft-Nelson S, Greipp PT, Garrity JA, Salomao DR and Garcia JJ: Adenoid cystic carcinoma of the lacrimal gland is frequently characterized by MYB rearrangement. Eye (Lond) 31: 720-725, 2017.

22. DeAngelis AF, Tsui A, Wiesenfeld D and Chandu A: Outcomes of patients with adenoid cystic carcinoma of the minor salivary glands. Int J Oral Maxillofac Surg 40: 710-714, 2011.

23. Guzzo M, Locati LD, Prott FJ, Gatta G, McGurk M and Licitra L: Major and minor salivary gland tumors. Crit Rev Oncol Hematol 74: 134-148, 2010.

24. Min R, Siyi L, Wenjun Y, Ow A, Lizheng W, Minjun D and Chenping Z: Salivary gland adenoid cystic carcinoma with cervical lymph node metastasis: A preliminary study of 62 cases. Int J Oral Maxillofac Surg 41: 952-957, 2012.

25. Kokemueller H, Eckardt A, Brachvogel P and Hausamen JE: Adenoid cystic carcinoma of the head and neck--a 20 years experience. Int J Oral Maxillofac Surg 33: 25-31, 2004.

26. Triantafillidou K, Dimitrakopoulos J, Iordanidis F, and Koufogiannis D: Management of adenoid cystic carcinoma of minor salivary glands. J Oral Maxillofac Surg 64: 1114-1120, 2006.

27. Ellington CL, Goodman M, Kono SA, Grist W, Wadsworth T, Chen AY, Owonikoko T, Ramalingam S, Shin DM, Khuri FR, et al: Adenoid cystic carcinoma of the head and neck: Incidence and survival trends based on 1973-2007 Surveillance, Epidemiology, and End Results data. Cancer 118: 4444-4451, 2012.

28. da Cruz Perez DE, de Abreu Alves F, Nobuko Nishimoto I, de Almeida OP and Kowalski LP: Prognostic factors in head and neck adenoid cystic carcinoma. Oral Oncol 42: 139-146, 2006.

29. Kataoka A, Iwamoto T, Tokunaga E, Tomotaki A, Kumamaru H, Miyata H, Niikura N, Kawai M, Anan K, Hayashi N, et al: Young adult breast cancer patients have a poor prognosis independent of prognostic clinicopathological factors: A study from the Japanese Breast Cancer Registry. Breast Cancer Res Treat 160: 163-172, 2016.

30. Liu S, Feng F, Xu G, Liu Z, Tian Y, Guo M, Lian X, Cai L, Fan D and Zhang $\mathrm{H}$ : Clinicopathological features and prognosis of gastric cancer in young patients. BMC Cancer 16: 478, 2016.

31. Sgaramella N, Lindell Jonsson E, Boldrup L, Califano L, Coates PJ, Tartaro G, Lo Muzio L, Fåhraeus R, Colella G, Dell'Aversana Orabona $\mathrm{G}$, et al: High expression of podoplanin in squamous cell carcinoma of the tongue occurs predominantly in patients $\leq 40$ years but does not correlate with tumour spread. J Pathol Clin Res 2: 3-8, 2015.

32. Zhou YE, O'Rourke JP, Edwards JS and Ness SA: Single molecule analysis of c-myb alternative splicing reveals novel classifiers for precursor B-ALL. PLoS One 6: e22880, 2011.

33. Glasspool RM, Brown R, Gore ME, Rustin GJ, McNeish IA, Wilson RH, Pledge S, Paul J, Mackean M, Hall GD, et al: A randomised, phase II trial of the DNA-hypomethylating agent 5-aza-2'-deoxycytidine (decitabine) in combination with carboplatin vs carboplatin alone in patients with recurrent, partially platinum-sensitive ovarian cancer. Br J Cancer 110: 1923-1929, 2014.

34. Barrett AW and Speight PM: Perineural invasion in adenoid cystic carcinoma of the salivary glands: A valid prognostic indicator? Oral Oncol 45: 936-940, 2009.

35. Gondivkar SM, Gadbail AR, Chole R, and Parikh RV: Adenoid cystic carcinoma: A rare clinical entity and literature review. Oral Oncol 47: 231-236, 2011.

36. Gomez DR, Hoppe BS, Wolden SL, Zhung JE, Patel SG, Kraus DH, Shah JP, Ghossein RA and Lee NY: Outcomes and prognostic variables in adenoid cystic carcinoma of the head and neck: A recent experience. Int J Radiat Oncol Biol Phys 70: 1365-1372, 2008.

37. Mendoza PR, Jakobiec FA and Krane JF: Immunohistochemical features of lacrimal gland epithelial tumors. Am J Ophthalmol 156: 1147-1158.e1, 2013.

38. Persson M, Andrén Y, Moskaluk CA, Frierson HF Jr, Cooke SL, Futreal PA, Kling T, Nelander S, Nordkvist A, Persson F and Stenman G: Clinically significant copy number alterations and complex rearrangements of MYB and NFIB in head and neck adenoid cystic carcinoma. Genes Chromosomes Cancer 51: 805-817, 2012. 